\title{
Effects of subclinical hypothyroidism on maternal and obstetric outcomes during pregnancy
}

\author{
Simten Genç®, Başak Cıngıllığglu® \\ Department of Obstetrics and Gynecology, Prof. Dr. Cemil Taşcıŏglu City Hospital, İstanbul, Turkey
}

\begin{abstract}
Objectives: Subclinical hypothyroidism has been defined as normal free thyroxine (FT4) with elevated thyroid stimulating hormone (TSH) levels. The aim of this study is to examine the relationship between the first trimester subclinical hypothyroidism with adverse obstetric outcomes in pregnant women.

Methods: This retrospective cohort study was conducted by examining the pregnant women who applied to the Gynecology Department of Okmeydani Training and Research Hospital at their $6^{\text {th }}$ to $14^{\text {th }}$ gestational weeks and had antenatal follow-ups between February 1, 2017 and December 31, 2020.

Results: Fetal weight (OR: 1; 95\% CI, 0.99-1.03, $p=0.023$ ), gestational age at delivery (OR: 0.91; 95\% CI, $0.83-0.99, p=0.022$ ), and preterm delivery (OR: $0.79 ; 95 \% \mathrm{CI}, 0.48-1.06, p=0.005$ ) were found to be statistically significant parameters in univariate risk analyses performed in the group whith patients normal T4 levels and TSH levels $\geq 2.5-4 \mathrm{mIU} / \mathrm{L}$. Lower gestational age at delivery (OR: $1 ; 95 \% \mathrm{CI}, 0.93-1.88, p=$ 0.016 ), and higher preterm delivery rates (OR: 0.99; 95\% CI, 0.96-1.01, $p=0.003$ ) were found to be statistically significant in multivariate risk analysis.

Conclusions: The rate of preterm delivery was statistically higher, and fetal weight and week of delivery were significantly lower in the group of pregnant women diagnosed with $\mathrm{SCH}$ having TSH values between 2.5 and $4 \mathrm{mIU} / \mathrm{L}$.
\end{abstract}

Keywords: Pregnancy, preterm birth, subclinical hypothyroidism

T hyroid diseases are frequently seen during pregnancy. The frequency of thyroid disorders in pregnancy is $2-3 \%$. It can be overt hypothyroidism, subclinical hypothyroidism or hyperthyroidism [1]. Elevated serum levels of thyroid stimulating hormone (TSH) greater than $10 \mathrm{mIU} / \mathrm{L}$ and/or lower free thyroxine (fT4) levels are observed in overt hypothyroidism. However, subclinical hypothyroidism has been defined as normal FT4 with elevated TSH levels $[2,3]$. Size of the thyroid gland increases by $10 \%$ in iodine-rich, and by $20-40 \%$ in iodine deficient countries [4]. Maternal thyroid hormone regulates fetal growth and development through transplacental trans- fer between the first 18-20 weeks of pregnancy and plays an important role in the development of fetal brain [5].

Since fetal thyroid tissue does not mature before 12-14 weeks of pregnancy, maternal fT4 is the only source of thyroid hormone for the developing fetus. In early pregnancy, maternal thyroid hormones are required for neural proliferation and migration. From mid-pregnancy, both maternal and fetal thyroid hormones are crucial for neurogenesis, neuronal migration, axonal growth, dendritic arborization, and synaptogenesis [6].

During pregnancy, many physiological changes

2How to cite this article: Genç S, Cingllloğlu B. Effects of subclinical hypothyroidism on maternal and obstetric outcomes during pregnancy. European Res J 2022;8(2):247-255. DOI: 10.18621/eurj.1010682

Address for correspondence: Simten Genç, MD., Prof. Dr. Cemil Taşcioglu City Hospital, Department of Obstetrics and Gynecology, Darulaceze Cad., No:25, Okmeydant, 34384 Şişli, Istanbul, Turkey.E-mail: simtengenc@yahoo.com.tr, Tel (Mobil): +90 542 4216854, Fax:+90212 221 7800 
occur in the thyroid gland in women. From the 4th-8th weeks of pregnancy, thyroxine-binding globulin (TBG) levels double in circulation due to the increase in estrogen production and total T4 and T3 concentrations increase in the first half of pregnancy and reach a plateau at the 20th gestational week. Human chorionic gonadotropin (hCG) hormone shows thyrotropic activity [7]. During the first trimester, a temporary increase in free thyroxine (FT4) and a decrease in thyroid-stimulating hormone (TSH) levels are observed. Later on, while FT4 concentration decreases by 10 $15 \%$, TSH returns to normal values. With these variations the reference intervals of both FT4 and TSH change throughout pregnancy [8].

According to recommendations of 2011 American Thyroid Association (ATA) guidelines, trimester specific- reference ranges have been established. Indeed, TSH values should be $0.1-2.5 \mathrm{mIU} / \mathrm{L}$ in the first, $0.2-$ $3.0 \mathrm{mIU} / \mathrm{L}$ in the second, and $0.3-3.5 \mathrm{mIU} / \mathrm{L}$ in the third trimesters [9]. In some studies, as recommended by the National Academy of Clinical Biochemistry (NACB), values ranging between 2.5 th and 97.5 th percentiles are accepted as normal [10]. However, ATA revised its recommendations in 2017 and if the prepregnancy TSH value is unknown, $4.0 \mathrm{mIU} / \mathrm{L}$ has been accepted as the upper limit of normal (ULN) of cutoff value [4].

There are studies showing the relationship between maternal thyroid diseases and preterm birth, birth weight, gestational diabetes mellitus, and preeclampsia $[11,12]$. Overt hypothyroidism is treated without hesitation, but there is no clear consensus on the treatment of subclinical hypothyroidism.

In the present study, universal screening of thyroid function was conducted in a pregnant population and the prevalence of $\mathrm{SCH}$ in antenatal pregnant women was investigated. The aim of this study is to examine the relationship between the first trimester subclinical hypothyroidism with adverse obstetric outcomes in pregnant women.

\section{METHODS}

This retrospective cohort study was conducted by examining the pregnant women who applied to the Gynecology Department of Okmeydani Training and Research Hospital at their $6^{\text {th }}$ to $14^{\text {th }}$ gestational weeks and had antenatal follow-ups between February 1, 2017 and December 31, 2020. Gestational age was calculated according to the last menstrual period or findings of ultrasound performed before the 20th gestational week. Gravida, parity, number of abortions, gestational weeks of all patients were recorded. Written consent was obtained from all pregnant women for delivery. Multipl pregnancy, smokers, alcohol users, pregnant women under 18 years old, those with diagnoses of chromosomal anomalies, maternal heart disease, history of autoimmune disorders, chronic drug users, overt thyroid disorder, or pregnants who were treated previously or presently with thyroxin or antithyroid drugs, were not included in this study.

Maternal blood samples were obtained from all mothers at first trimester visit after an also overnight fasting. Maternal thyroid stimulating hormone (TSH) and free thyroxine (fT4) levels were measured in routine antenatal follow-ups. All data were entered in a computerized database.

In our laboratory, reference ranges for serum TSH (0.27-4.2 mIU/L), and f T4 (0.93-1.6 ng/dl) were determined as indicated. However, since in some studies, normal T4 values in pregnant women were accepted as ranging between $0.8-1.53 \mathrm{ng} / \mathrm{dl}$ for the first trimester, these values were also taken as normal values in our study [13].

The 2011 American Thyroid Association (ATA) guidelines accepted the upper limit of normal of the first trimester TSH as $2.5 \mathrm{mIU} / \mathrm{L}$, but in 2017 the ULN was revised as $4 \mathrm{mIU} / \mathrm{L}[4,9]$. Therefore, both values were used separately in our study.

Pregnant women with normal TSH and fT4 levels were considered to be euthyroid and served as control subjects (Group 1). Patients with normal T4 levels and TSH levels $\geq 2.5-4 \mathrm{mIU} / \mathrm{L}$ were included in Group 2, and patients with normal T4 levels and TSH levels $\geq$ 4-10 mIU/L were included in Group 3.

Although our study started with 878 pregnant women, 804 patients were selected as the study group because 74 patients did not have subclinical hypothyroidism and normal values. Gestational week at delivery, fetal weight, type of delivery, indications for cesarean section and gender of the newborns were recorded. Besides, maternal, and obstetric outcomes as preeclampsia, oligohydramios, polyhydramnios, large for gestational age (LGA), small for gestational age (SGA), preterm birth, postterm birth, preterm pre- 
mature rupture of membranes (PPROM), premature rupture of membranes (PROM), low birth weight (LBW), gestational diabetes mellitus (GDM), fetal demise, macrosomia were recorded.

The diagnosis of oligohydramnios was defined ultrasonographically as the amniotic fluid index less than $2 \mathrm{~cm}$ in a single quadrant and less than $5 \mathrm{~cm}$ in the total of 4 quadrants. Polyhydroamnios, on the other hand, was defined as amniotic fluid index over $8 \mathrm{~cm}$ in a single quadrant and over $20 \mathrm{~cm}$ in total of 4 quadrants. The diagnosis of GDM was made with a 2 step procedure as recommended by the American College of Obstetricians and Gynecologists (AGOC) [14].

Intrauterine fetal death after 24 weeks of gestation was defined as fetal demise. Macrosomia was defined as fetal weight above $4000 \mathrm{~g}$ and low birth weight was considered when it was below $2500 \mathrm{~g}$. Births before 37 weeks of gestation were termed as premature births, and deliveries over 42 weeks were called postterm births. Birthweights below the $10^{\text {th }}$ percentile were termed as SGA, and LGA if they were over the 90th percentile.

The diagnosis of preeclampsia was made according to the criteria set by the International Society for the Study of Hypertension in Pregnancy [15].

Rupture of fetal membranes before the onset of labor was termed as premature rupture of membranes (PROM), while rupture of membranes before 37th gestational week was designated as preterm premature rupture of membranes (PPROM).

\section{Ethical Approval}

This study was performed in line with the principles of the Declaration of Helsinki. Approval was granted by the Ethics Committee of University of Health Sciences, Okmeydanı Training and Research Hospital (Date: 10/08/2021/No: 48670771514.10./297).

\section{Statistical Analysis}

In this study, statistical analyzes were performed with NCSS (Number Cruncher Statistical System) 2007 Statistical Software (Utah, USA) package program. In addition to descriptive statistical methods (mean, standard deviation, median, interquartile range) used in the evaluation of the data, the distribution of the variables was examined with the ShapiroWilk normality test. For pairwise comparison of the variables with normal distribution, the independent ttest, while for pairwise comparison of the groups of non-normally distributed variables the Mann-Whitney U test were utilized. Chi-square and Fisher's exact tests were used in the comparison of qualitative data. Univariate and multivariate risks of the groups were determined by logistic regression analysis. The results were evaluated at the significance level of $p<0.05$.

\section{RESULTS}

A total of 804 patients included in our study were divided into 3 groups according to their T4 and TSH values. Group 1 was chosen as the control group, while Groups 2 and 3 were defined as the groups with subclinical hypothyroidism as follows: Group 1 ( $\mathrm{n}=$ 592) T4 normal and TSH $=0.1-2.5 \mathrm{mIU} / \mathrm{L}$; Group 2 $(\mathrm{n}=146)$ T4 normal and TSH $\geq 2.5-4 \mathrm{mIU} / \mathrm{L}$; Group $3(\mathrm{n}=66)$, T4 normal and TSH $\geq 4-10 \mathrm{mIU} / \mathrm{L}$.

Demographic characteristics of the patients and maternal and fetal adverse obstetric outcomes are shown in Table 1 and Table 2. When Groups 1 and 2 were compared with each other, no statistically significant difference was observed between the 2 groups as for maternal age, delivery type, cesarean section indications, gravida, parity and abortion averages, test week, and gender distributions. For all these parameters, no significant difference was found when Groups 1 and 3 were compared with each other.

Fetal weight averages and mean gestational age at delivery in Group 2 were found to be statistically significantly lower than Group 1 ( $p=0.023$ and $p=0.044$ respectively). However, no statistically significant difference was observed between Groups 1 and 3 as for fetal weight averages and mean gestational age at delivery.

Regarding obstetric outcomes, any statistically significant difference was not observed between Groups 1 and 2 and also between Groups 1 and 3 as for abruptio placentae, preeclampsia, GDM, PPROM, PROM, SGA, fetal demise, macrosomia, LBW, postterm birth, need for neonatal intensive care unit, oligohydramnios, polyhydramnios, and LGA.

The frequency of preterm births in Group 2 was statistically significantly higher than Group 1 ( $p=$ 0.004). However, no statistically significant difference was observed between Groups 1 and 3 as for the the 
Table 1. Demographic characteristics

\begin{tabular}{|c|c|c|c|c|c|c|}
\hline \multicolumn{2}{|c|}{ 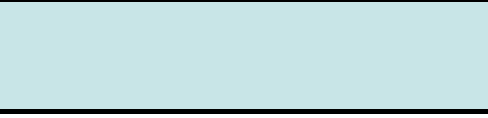 } & $\begin{array}{c}\text { Group } 1 \\
(n=592)\end{array}$ & $\begin{array}{c}\text { Group } 2 \\
(n=146)\end{array}$ & $\begin{array}{c}\text { Group } 3 \\
(n=66)\end{array}$ & $\begin{array}{c}p \text { value } \\
\text { G1-G2 }\end{array}$ & $\begin{array}{c}p \text { value } \\
\text { G1-G3 }\end{array}$ \\
\hline \multicolumn{2}{|c|}{$\operatorname{Age}($ mean \pm SD $)$} & $29.42 \pm 5.81$ & $29.34 \pm 5.95$ & $29.7 \pm 6.84$ & $0.886^{*}$ & $0.715^{*}$ \\
\hline \multicolumn{2}{|c|}{ Delivery, n (\%) } & & & & $0.847^{+}$ & $0.532^{+}$ \\
\hline \multicolumn{2}{|c|}{ Vaginal } & $281(47.47)$ & $68(46.58)$ & $34(51.52)$ & & \\
\hline \multicolumn{2}{|c|}{ Cesarean } & $311(52.53)$ & $78(53.42)$ & $32(48.48)$ & & \\
\hline \multicolumn{2}{|c|}{$\begin{array}{l}\text { Indications for cesarean } \\
\text { sections, } \mathbf{n}(\%)\end{array}$} & & & & $0.346^{+}$ & $0.928^{+}$ \\
\hline \multicolumn{2}{|c|}{ Previous Cesarean } & $179(57.37)$ & $49(62.82)$ & $22(68.75)$ & & \\
\hline \multicolumn{2}{|c|}{ Fetal Distress } & $50(16.03)$ & $13(16.67)$ & $3(9.38)$ & & \\
\hline \multicolumn{2}{|c|}{ Progress failure } & $24(7.69)$ & $5(6.41)$ & $2(6.25)$ & & \\
\hline \multicolumn{2}{|c|}{$\begin{array}{l}\text { Cephalopelvic } \\
\text { disproportion }\end{array}$} & $24(7.69)$ & $5(6.41)$ & $3(9.38)$ & & \\
\hline \multicolumn{2}{|c|}{ Macrosomia } & $14(4.49)$ & $0(0.00)$ & $1(3.13)$ & & \\
\hline \multicolumn{2}{|c|}{ Malpresantation } & $17(5.45)$ & $4(5.13)$ & $1(3.13)$ & & \\
\hline \multicolumn{2}{|c|}{ Placenta previa } & $2(0.64)$ & $0(0.00)$ & $0(0.00)$ & & \\
\hline \multicolumn{2}{|c|}{ Cord prolapsus } & $0(0.00)$ & $1(1.28)$ & $0(0.00)$ & & \\
\hline \multicolumn{2}{|c|}{ Maternal factor } & $2(0.64)$ & $1(1.28)$ & $0(0.00)$ & & \\
\hline \multirow[t]{2}{*}{ Gravida } & $\operatorname{Mean} \pm$ SD & $2.75 \pm 1.48$ & $2.75 \pm 1.36$ & $2.53 \pm 1.36$ & $0.689^{\ddagger}$ & 0.234 \\
\hline & median (IQR) & $3(2-4)$ & $3(2-4)$ & $2(2-3)$ & & \\
\hline \multirow[t]{2}{*}{ Parity } & Mean \pm SD & $1.36 \pm 1.17$ & $1.33 \pm 1.08$ & $1.17 \pm 0.97$ & $0.960^{\ddagger}$ & $0.295^{\ddagger}$ \\
\hline & median (IQR) & $1(0.25-2)$ & $1(0-2)$ & $1(0-2)$ & & \\
\hline \multirow[t]{2}{*}{ Abortus } & Mean \pm SD & $0.4 \pm 0.84$ & $0.42 \pm 0.75$ & $0.36 \pm 0.8$ & $0.564^{\ddagger}$ & $0.627^{*}$ \\
\hline & median (IQR) & $0(0-1)$ & $0(0-1)$ & $0(0-1)$ & & \\
\hline \multicolumn{2}{|c|}{ Test weeks $($ mean \pm SD) } & $8.06 \pm 2.29$ & $7.94 \pm 2.44$ & $8.08 \pm 2.62$ & $0.597^{*}$ & $0.929 *$ \\
\hline \multicolumn{2}{|c|}{ Fetal Weight $($ mean \pm SD) } & $3272.16 \pm 544.02$ & $3156.61 \pm 560.61$ & $3299.02 \pm 443.94$ & $0.023 *$ & $0.699 *$ \\
\hline \multicolumn{2}{|c|}{ Gestational age (mean \pm SD) } & $38.59 \pm 1.83$ & $38.17 \pm 2.31$ & $38.76 \pm 1.44$ & $0.044 *$ & $0.463 *$ \\
\hline \multicolumn{2}{|c|}{ Gender, n (\%) } & & & & $0.268^{+}$ & $0.337^{+}$ \\
\hline \multicolumn{2}{|c|}{ Female } & $306(51.69)$ & $68(46.58)$ & $30(45.45)$ & & \\
\hline \multicolumn{2}{|c|}{ Male } & $286(48.31)$ & $78(53.42)$ & $36(54.55)$ & & \\
\hline
\end{tabular}

*Independent $\mathrm{t}$ test, ${ }^{+}$Chi-Square test, ${ }^{\dagger}$ Fisher's Exact Test, Group $1=\mathrm{T} 4$ normal $(0.8-1.53 \mathrm{ng} / \mathrm{dl})$, TSH = 0.1-2.5 mIU/L, Group $2=\mathrm{T} 4$ normal $(0.8-1.53 \mathrm{ng} / \mathrm{dl}), \mathrm{TSH} \geq 2.5-4 \mathrm{mIU} / \mathrm{L}$, Group $3=\mathrm{T} 4$ normal $(0.8-1.53 \mathrm{ng} / \mathrm{dl}), \mathrm{TSH} \geq 4-10 \mathrm{mIU} / \mathrm{L}$

distribution of preterm births.

Univariate and multivariate logistic regression risk analyzes were performed for Group 2 (Table 3). Fetal weight (OR: 1; 95\% CI, 0.99-1.03, $p=0.023$ ), gestational age at delivery (OR: 0.91; 95\% CI, 0.83-0.99, $p$ $=0.022)$, and preterm delivery (OR: $0.79 ; 95 \% \mathrm{CI}$, $0.48-1.06, p=0.005$ ) were found to be statistically significant parameters in univariate risk analyses performed in Group 2.

Maternal age and parity were adjusted by perform- ing a multivariate risk analysis. Lower gestational age at delivery (OR: $1 ; 95 \% \mathrm{CI}, 0.93-1.88, p=0.016$ ), and higher preterm delivery rates (OR: 0.99 ; $95 \% \mathrm{CI}, 0.96-$ $1.01, p=0.003$ ) were found to be statistically significant in multivariate risk analysis.

Univariate and multivariate logistic regression risk analysis were performed for Group 3 (Table 4). No statistical significance was observed in the variables examined in Group $3(p>0.05)$ 
Table 2. Adverse obstetric outcomes

\begin{tabular}{lcccccccc}
\hline & $\begin{array}{c}\text { Group 1 } \\
(\mathbf{n}=\mathbf{5 9 2})\end{array}$ & $\begin{array}{c}\text { Group 2 } \\
(\mathbf{n}=\mathbf{1 4 6})\end{array}$ & $\begin{array}{c}\text { Group 3 } \\
(\mathbf{n}=\mathbf{6 6})\end{array}$ & $\boldsymbol{p}$ value & $\boldsymbol{p}$ value \\
\hline Abruptio placentae & $\mathbf{n}$ & $\mathbf{\%}$ & $\mathbf{n}$ & $\mathbf{\%}$ & $\mathbf{n}$ & $\mathbf{\%}$ & $\mathbf{G 1 - G 2}$ & $\mathbf{G 1 - G 3}$ \\
\hline Preeclampsia & 4 & 0.68 & 0 & 0.00 & 0 & 0.00 & $0.319^{\ddagger}$ & $0.503^{\ddagger}$ \\
\hline GDM & 23 & 3.89 & 8 & 5.48 & 0 & 0.00 & $0.390^{+}$ & $0.103^{\ddagger}$ \\
\hline PPROM & 52 & 8.78 & 16 & 10.96 & 8 & 12.12 & $0.416^{+}$ & $0.372^{+}$ \\
\hline PROM & 12 & 2.03 & 1 & 0.68 & 2 & 3.03 & $0.270^{\ddagger}$ & $0.592^{\ddagger}$ \\
\hline SGA & 45 & 7.60 & 11 & 7.53 & 5 & 7.58 & $0.978^{+}$ & $0.994^{+}$ \\
\hline Fetal demise & 30 & 5.07 & 10 & 6.85 & 5 & 7.58 & $0.394^{+}$ & $0.389^{+}$ \\
\hline Makrosomia & 4 & 0.68 & 0 & 0.00 & 0 & 0.00 & $0.319^{\ddagger}$ & $0.503^{\ddagger}$ \\
\hline LBW & 43 & 7.26 & 5 & 3.42 & 5 & 7.58 & $0.092^{+}$ & $0.926^{+}$ \\
\hline Preterm birth & 40 & 6.6 & 13 & 8.90 & 1 & 1.52 & $0.368^{+}$ & $0.095^{\ddagger}$ \\
\hline Postterm birth & 62 & 10.47 & 28 & 19.18 & 7 & 10.61 & $\mathbf{0 . 0 0 4}^{+}$ & $0.973^{+}$ \\
\hline Neonatal intensive care & 1 & 0.17 & 1 & 0.68 & 0 & 0.00 & $0.283^{\ddagger}$ & $0.738^{\ddagger}$ \\
\hline Oligohydramnios & 26 & 4.39 & 6 & 4.11 & 1 & 1.52 & $0.881^{+}$ & $0.264^{\ddagger}$ \\
\hline Polyhidramnios & 8 & 1.35 & 4 & 2.74 & 2 & 3.03 & $0.235^{+}$ & $0.290^{\ddagger}$ \\
\hline LGA & 14 & 2.36 & 5 & 3.42 & 0 & 0.00 & $0.469^{+}$ & $0.207^{\ddagger}$ \\
\hline
\end{tabular}

+Chi-square test, $\neq$ Fisher's Exact Test.LGA $=$ Large for gestational age, $\mathrm{SGA}=$ Small for gestational age, $\mathrm{GDM}=$ Gestational Diabetes Mellitus, PROM $=$ Premature rupture of membrane, PPROM $=$ Preterm premature rupture of membrane, $\mathrm{LBW}=$ Low birth weight

Group $1=\mathrm{T} 4$ normal $(0.8-1.53 \mathrm{ng} / \mathrm{dl}), \mathrm{TSH}=0.1-2.5 \mathrm{mIU} / \mathrm{L}$

Group $2=\mathrm{T} 4$ normal $(0.8-1.53 \mathrm{ng} / \mathrm{dl}), \mathrm{TSH} \geq 2.5-4 \mathrm{mIU} / \mathrm{L}$

Group $3=\mathrm{T} 4$ normal $(0.8-1.53 \mathrm{ng} / \mathrm{dl}), \mathrm{TSH} \geq 4-10 \mathrm{mIU} / \mathrm{L}$

Table 3. Results of univariate and multivariate logistic regression risk analysis performed for Group 2 with TSH levels $\geq 2.5-4 \mathrm{mIU} / \mathrm{L}$

\begin{tabular}{lcccc}
\hline & \multicolumn{2}{c}{ Univariate risk } & \multicolumn{2}{c}{ Multivariate risk } \\
& OR (95\% CI) & $\boldsymbol{p}$ value & OR (95\% CI) & $\boldsymbol{p}$ value \\
\hline Fetal weight & $1.00(0.99-1.03)$ & $\mathbf{0 . 0 2 3}$ & $1.01(0.87-1.57)$ & 0.058 \\
Gestational age & $0.91(0.83-0.99)$ & $\mathbf{0 . 0 2 2}$ & $1.09(0.93-1.88)$ & $\mathbf{0 . 0 1 6}$ \\
Preterm delivery & $0.79(0.48-1.06)$ & $\mathbf{0 . 0 0 5}$ & $0.99(0.96-1.01)$ & $\mathbf{0 . 0 0 3}$ \\
\hline
\end{tabular}

In multivariate analysis ORs adjusted for maternal age and parity.

Group $2=\mathrm{T} 4$ normal $(0.8-1.53 \mathrm{ng} / \mathrm{dl}), \mathrm{TSH} \geq 2.5-4 \mathrm{mIU} / \mathrm{L}$

\section{DISCUSSION}

Subclinical hypothyroidism is a condition characterized with increased thyroid stimulating hormone (TSH) levels with normal free thyroxine (fT4) levels without any symptoms of hypothyroidism. Although a correlation was found between adverse maternal outcomes and overt maternal hypothyroidism, the rela- tionship between subclinical hypothyroidism ( $\mathrm{SCH}$ ) in pregnancy and perinatal complications is not clear. There is no clear consensus on the normal and cut-off values of TSH in pregnancy. Therefore, in our study we found it appropriate to examine pregnant women with $\mathrm{SCH}$ in 2 separate groups.

In our study, the rate of preterm delivery was statistically higher, and fetal weight and week of delivery 


\section{Table 4. Results of univariate and multivariate logistic regression risk analysis performed for Group 3 with TSH levels $\geq 4-10 \mathrm{mIU} / \mathrm{L}$}

\begin{tabular}{lcccc}
\hline & \multicolumn{2}{c}{ Univariate risk } & Multivariate risk \\
& OR (95\% CI) & $\boldsymbol{p}$ value & OR (95\% CI) & $\boldsymbol{p}$ value \\
\hline Fetal weight & $1.00(0.94-1.07)$ & 0.698 & & \\
Gestational age & $1.06(0.91-1.23)$ & 0.462 & & \\
Preterm delivery & $0.99(0.43-2.25)$ & 0.973 & & 0.715 \\
\hline LBW & $2.71(0.65-4.83)$ & 0.129 & $0.99(0.97-1.02)$ & \\
\hline
\end{tabular}

In multivariate analysis ORs adjusted for maternal age and parity.

Group 3 = T4 normal (0.8-1.53 ng/dl), TSH $\geq 4-10 \mathrm{mIU} / \mathrm{L}$

were significantly lower in the group of pregnant women diagnosed with SCH having TSH values between 2.5 and $4 \mathrm{mIU} / \mathrm{L}$, when compared to pregnant women with normal thyroid function test results. However, no statistically significant adverse obstetric outcomes were encountered in pregnant women with SCH having TSH values between 4 and $10 \mathrm{mIU} / \mathrm{L}$.

There is no clear consensus on universal application of thyroid function screening tests before pregnancy. Some clinicians recommend testing especially around the 9th gestational week at the first antenatal visit, while others recommend screening high-risk women. The optimal time for thyroid function tests is at the end of the first trimester or before pregnancy in high-risk pregnant women [16]. In our study group, we performed this screening test at a mean 8.02 gestational weeks namely at the first trimester antenatal visit as recommended.

$\mathrm{SCH}$ is considered as a milder thyroid function test abnormality and is seen more frequently than overt maternal hypothyroidism. Overt hypothyroidism has a prevalence of $0.2-0.5 \%$. However, the prevalence of $\mathrm{SCH}$ in pregnancy is between $2 \%$ and $2.5 \%$ [17]. In our study, when all $\mathrm{SCH}$ cases with TSH cut-off values above $2.5 \mathrm{mIU} / \mathrm{L}$ were examined, the prevalence rate was found to be $24.14 \%$. However, when the TSH cutoff value was taken as $4 \mathrm{mIU} / \mathrm{L}$, the prevalence of $\mathrm{SCH}$ was found to be $7.5 \%$. Unlike other studies, these rates were extremely high. The reason may be that our hospital is a tertiary center and too many patients are followed up during the antenatal period.

It is not always easy to determine cut-off values for normal TSH levels. Geographic and ethnic diversity may also have a significant effect on TSH and FT4 reference limits in pregnancy $[18,19]$. In a study from
India the authors used 5th to 95th percentile as normal reference range. The upper limit of normal for TSH in the first trimester was 5.0-6.0 mIU/L [20, 21]. However, in another study from India, the researchers concluded that it was more accurate to accept $3.0 \mathrm{mIU} / \mathrm{L}$ as the cut-off value of TSH for SCH instead of 4.0 $\mathrm{mIU} / \mathrm{L}$ as accepted in the revised ATA 2017 guidelines [22]. However, we examined fetal and maternal outcomes in 2 separate groups by taking both $2.5 \mathrm{mIU} / \mathrm{L}$ and $4 \mathrm{mIU} / \mathrm{L}$ as TSH cut-off values for $\mathrm{SCH}$. We thought that we could get more accurate results in this study.

In the study by Chen et al. [23], 4.63\% of pregnant women were diagnosed with $\mathrm{SCH}$ when all trimesters were examined without discrimination. Risks of gestational hypertension, SGA, LBW and PROM were relatively higher in pregnant women with $\mathrm{SCH}$. There was no significant difference in the incidence of fetal distress, stillbirth, GDM, placenta previa, placental abruption, and preterm birth. However, when the first trimester was examined separately, and normal TSH levels were taken as 0.09-3.47 mIU/L, any difference was not found between groups with SCH and euthyroid in terms of obstetric outcomes [23].

In the study of Casey et al. [24], premature birth before 34 weeks of gestation was observed 2 times more frequently in women with $\mathrm{SCH}$. However, in other studies, no significant difference was found regarding rates of preterm delivery in $\mathrm{SCH}[23,25]$. In our study, preterm birth was seen at a rate of $19.18 \%$ in the group with TSH values ranging between 2.5 and $4 \mathrm{mIU} / \mathrm{L}$ which were found to be statistically significantly higher when compared to the euthyroid group. $(p=0.004)$ In the univariate and multivariate logistic regression analyses, statistically significantly higher 
rates of preterm birth $(p=0.005, p=0.003$ respectively) were detected. However, no significant difference was found as for preterm birth rates in the group with TSH levels ranging between 4 and $10 \mathrm{mIU} / \mathrm{L}$. It was suprising that there was less premature birth in this group.

In one study, an increased risk of severe preeclampsia was found in pregnant women with $\mathrm{SCH}$ compared to the euthyroid group [26]. In another study, placental abruption was observed 3 times more frequently in pregnant women with $\mathrm{SCH}$ compared to the normal group [24]. However, in our study, no increased risk was found in rates of either preeclampsia or placental abruption in pregnant women with $\mathrm{SCH}$.

In the study of Monen et al. [27], maternal TSH $\geq$ 97.5th percentile in the first and third trimesters was correlated with SGA, but no relationship was found between maternal FT4 levels and SGA. In another study, $16.52 \%$ of pregnant women who gave birth to babies with SGA were in the SCH group [28]. In our study, SGA was found at a rate of $7 \%$ in the $\mathrm{SCH}$ group and $33.33 \%$ of the pregnant women who gave birth to a baby with SGA were detected in the SCH group. However, any statistically significant difference was not found between the group with $\mathrm{SCH}$, and the euthyroidism as for the rate of SGA.

In the study of Cleary-Goldman et al. [29], no relationship was found with subclinical hypothyroidism and adverse outcomes. In their studies, a relationship was found between overt hypothyroidism and GDM, but no relationship was detected between GDM, and $\mathrm{SCH}$ in pregnant women [29]. However, in a large population-based study, the risk of GDM was found to be associated with increased TSH during pregnancy [30]. In our study, GDM was found at rates of $10.96 \%$, and $12.12 \%$ in the groups with TSH levels between 2.5-4 mIU/L, and 4-10 mIU/L, respectively without any increased risk in GDM in all patients with SCH.

In another study, pregnants under 20 gestational weeks were examined and the $5-95^{\text {th }}$ percentile was considered normal for TSH. No correlation was found between thyroid status and stillbirth rate. While stillbirth rate increased at TSH levels above $10 \mathrm{mU} / \mathrm{L}$, any corresponding increase was not observed in the incidence of SCH [24]. In our study, fetal demise was not observed in the SCH patient group. In the study of Negro et al. [25], the group with TSH levels between 2.5 and $5.0 \mathrm{mIU} / \mathrm{L}$ group was compared with the eu- thyroid group, and pregnancy loss was found to be significantly higher in the SCH group. They found an increased risk in gestational diabetes and stillbirth in subsequent pregnancies in patients who were diagnosed with $\mathrm{SCH}$ in their previous pregnancies [31].Therefore, it is important to diagnose $\mathrm{SCH}$ during pregnancy and follow up these patients after delivery.

In a meta-analysis of 18 cohort studies, pregnant women with $\mathrm{SCH}$ were found to be at a higher risk for pregnancy loss, placental abruption, premature rupture of membranes, and neonatal death [32]. However, in this meta-analysis, the studies were performed in different trimesters. However, our study was conducted by screening only first trimester pregnant women and no increase in risk was detected in any of these adverse effects.

\section{Limitations}

We acknowledge that this study has some limitations Data related to race, ethnicity, iodine intake, maternal pre-pregnancy body mass index and socioeconomic status, were not analyzed in this study. When diagnosing $\mathrm{SCH}$, factors that affect TSH values such as gestational age and the time of day when the blood sample is obtained should also be considered. All the patients in our study were in the first trimester, and blood samples were drawn in the morning. We acknowledge that TSH cut-off values for the diagnosis of SCH differ in previous studies. Our study, unlike other studies, was conducted with two separate cut-off values and obstetric and maternal outcomes were examined separately.

\section{CONCLUSION}

The current study was performed to gain insight into the impact of $\mathrm{SCH}$ on maternal and perinatal outcomes. In pregnant women diagnosed with $\mathrm{SCH}$, and TSH values between 2.5 and $4 \mathrm{mIU} / \mathrm{L}$, the rate of preterm delivery was statistically significantly higher, and fetal weight and gestational week at birth were significantly lower. Routine maternal thyroid function testing is necessary to improve maternal and perinatal outcomes during the antenatal period, and especially in the first trimester. However, further prospective multicenter studies with large patient groups are needed. Performing thyroid function tests only on 
pregnant women with symptoms of thyroid disease or with a relevant personal history may be insufficient to predict pregnant women who may be in the high-risk pregnancy group.

\section{Authors' Contribution}

Study Conception: SG, BC; Study Design: SG, BC; Supervision: SG, BC; Funding: N/A; Materials: N/A; Data Collection and/or Processing: SG, BC; Statistical Analysis and/or Data Interpretation: SG; Literature Review: SG; Manuscript Preparation: SG and Critical Review: SG, BC.

\section{Conflict of interest}

The authors disclosed no conflict of interest during the preparation or publication of this manuscript.

\section{Financing}

The authors disclosed that they did not receive any grant during conduction or writing of this study.

\section{REFERENCES}

1. Negro R, Mestman JH. Thyroid disease in pregnancy. Best Pract Res Clin Endocrinol Metab 2011;25:927-43.

2. Garber JR, Cobin RH, Gharib H, Hennessey JV, Klein I, Mechanick JI, et al. American Association of Clinical Endocrinologists and American Thyroid Association Taskforce on Hypothyroidism in Adults. Clinical practice guidelines for hypothyroidism in adults: co-sponsored by the American Association of Clinical Endocrinologists and the American Thyroid Association. Endocr Pract 2012;18:988-1028.

3. Derakhshan A, Peeters RP, Taylor PN, Bliddal S, Carty DM, Meems M, et al. Association of maternal thyroid function with birthweight: a systematic review and individual-participant data meta-analysis. Lancet Diabetes Endocrinol 2020;8:501-10.

4. Alexander EK, Pearce EN, Brent GA, Brown RS, Chen H, Dosiou C, et al. 2017 Guidelines of the American Thyroid Association for the diagnosis and management of thyroid disease during pregnancy and the postpartum. Thyroid 2017;27:315-89.

5. Korevaar TIM, Medici M, Visser TJ, Peeters RP. Thyroid disease in pregnancy: new insights in diagnosis and clinical management. Nat Rev Endocrinol 2017;13:610-22.

6. Ausó E, Lavado-Autric R, Cuevas E, Del Rey FE, Morreale De Escobar G, Berbel P. A moderate and transient deficiency of maternal thyroid function at the beginning of fetal neocorticogenesis alters neuronal migration. Endocrinology 2004;145:403747.

7. Soldin OP, Tractenberg RE, Hollowell JG, Jonklaas J, Janicic N, Soldin SJ. Trimester-specific changes in maternal thyroid hormone, thyrotropin, and thyroglobulin concentrations during ges- tation: trends and associations across trimesters in iodine sufficiency. Thyroid 2004;14:1084-90.

8. Moleti M, Trimarchi F, Vermiglio F. Thyroid physiology in pregnancy. Endocr Pract 2014;20:589-96.

9. Stagnaro-Green A, Abalovich M, Alexander E, Azizi F, Mestman J, Negro R, et al. American Thyroid Association Taskforce on Thyroid Disease During Pregnancy and Postpartum. Guidelines of the American Thyroid Association for the diagnosis and management of thyroid disease during pregnancy and postpartum. Thyroid 2011;21:1081-125.

10. Baloch Z, Carayon P, Conte-Devolx B, Demers LM, FeldtRasmussen U, Henry JF et al. Guidelines Committee, National Academy of Clinical Biochemistry. Laboratory medicine practice guidelines. Laboratory support for the diagnosis and monitoring of thyroid disease. Thyroid 2003;13:3-126.

11. Wang J, Gong XH, Peng T, Wu JN. Association of thyroid function during pregnancy with the risk of preeclampsia and gestational diabetes mellitus. Endocr Pract 2021;27:819-25.

12. León G, Murcia M, Rebagliato M, Álvarez-Pedrerol M, Castilla AM, Basterrechea M, et al. Maternal thyroid dysfunction during gestation, preterm delivery, and birthweight. The Infancia y Medio Ambiente Cohort, Spain. Paediatr Perinat Epidemiol 2015;29:113-22.

13. Almomin AMS, Mansour AA, Sharief M. Trimester-specific reference intervals of thyroid function testing in pregnant women from Basrah, Iraq using electrochemiluminescent immunoassay. Diseases 2016;4:20.

14. Committee on Practice Bulletins-Obstetrics. ACOG Practice Bulletin No. 190: Gestational Diabetes Mellitus. Obstet Gynecol. 2018; 131:e49-e64.

15. Brown MA, Lindheimer MD, de Swiet M, Van Assche A, Moutquin JM. The classification and diagnosis of the hypertensive disorders of pregnancy: statement from the International Society for the Study of Hypertension in Pregnancy (ISSHP). Hpertens Pregnancy 2001;20:IX-XIV.

16. De Groot L, Abalovich M, Alexander EK, Amino N, Barbour L, Cobin RH, et al. Management of thyroid dysfunction during pregnancy and postpartum: an Endocrine Society clinical practice guideline. J Clin Endocrinol Metab 2012;97:2543-65.

17. Allan WC, Haddow JE, Palomaki GE, Williams JR, Mitchell ML, Hermos RJ, et al. Maternal thyroid deficiency and pregnancy complications: implications for population screening. J Med Screen 2000;7:127-30.

18. Benhadi N, Wiersinga WM, Reitsma JB, Vrijkotte TG, van der Wal MF, Bonsel GJ. Ethnic differences in TSH but not in free T4 concentrations or TPO antibodies during pregnancy. Clin Endocrinol (Oxf) 2007;66:765-70.

19. McNeil AR, Stanford PE. Reporting Thyroid Function Tests in Pregnancy. Clin Biochem Rev 2015;36:109-26.

20. Marwaha RK, Chopra S, Gopalakrishnan S, Sharma B, Kanwar RS, Sastry A, et al. Establishment of reference range for thyroid hormones in normal pregnant Indian women. BJOG 2008;115:602-6.

21. Kannan S, Mahadevan S, Sigamani A. A systematic review on normative values of trimester-specific thyroid function tests in Indian women. Indian J Endocrinol Metab 2018;22:7-12.

22. Kalra S, Agarwal S, Aggarwal R, Ranabir S. Trimester-spe- 
cific thyroid-stimulating hormone: an Indian perspective. Indian J Endocrinol Metab 2018;22:1-4.

23. Chen LM, Du WJ, Dai J, Zhang Q, Si GX, Yang H, et al. Effects of subclinical hypothyroidism on maternal and perinatal outcomes during pregnancy: a single-center cohort study of a Chinese population. PLoS One 2014;9:e109364.

24. Casey BM, Dashe JS, Wells CE, McIntire DD, Byrd W, Leveno KJ, et al. Subclinical hypothyroidism and pregnancy outcomes. Obstet Gynecol 2005;105:239-45.

25. Negro R, Schwartz A, Gismondi R, Tinelli A, Mangieri T, Stagnaro-Green A. Increased pregnancy loss rate in thyroid antibody negative women with TSH levels between 2.5 and 5.0 in the first trimester of pregnancy. J Clin Endocrinol Metab 2010;95:E44-8.

26. Wilson KL, Casey BM, McIntire DD, Halvorson LM, Cunningham FG. Subclinical thyroid disease and the incidence of hypertension in pregnancy. Obstet Gynecol 2012;119:315-20.

27. Monen L, Kuppens SM, Hasaart TH, Oosterbaan HP, Oei SG, Wijnen $\mathrm{H}$, et al. Maternal thyrotropin is independently related to small for gestational age neonates at term. Clin Endocrinol (Oxf). 2015;82:254-9.

28. Ohashi M, Furukawa S, Michikata K, Kai K, Sameshima H, Ikenoue T. Risk-based screening for thyroid dysfunction during pregnancy. J Pregnancy 2013;2013:619718.

29. Cleary-Goldman J, Malone FD, Lambert-Messerlian G, Sullivan L, Canick J, Porter TF, et al. Maternal thyroid hypofunction and pregnancy outcome. Obstet Gynecol 2008;112:85-92.

30. Tudela CM, Casey BM, McIntire DD, Cunningham FG. Relationship of subclinical thyroid disease to the incidence of gestational diabetes. Obstet Gynecol 2012;119:983-8.

31. Nelson DB, Casey BM, McIntire DD, Cunningham FG. Subsequent pregnancy outcomes in women previously diagnosed with subclinical hypothyroidism. Am J Perinatol 2014;31:77-84. 32. Maraka S, Ospina NM, O'Keeffe DT, Espinosa De Ycaza AE, Gionfriddo MR, Erwin PJ, et al. Subclinical hypothyroidism in pregnancy: a systematic review and meta-analysis. Thyroid 2016;26:580-90. 